\title{
Scouring due to submerged sills
}

\author{
Ashley Dudill ${ }^{1,2}$, Jose Vasquez ${ }^{2}$, and Dave Mclean $^{2}$ \\ ${ }^{1}$ Department of Geography, University of British Columbia, Vancouver, Canada \\ ${ }^{2}$ Northwest Hydraulic Consultants Ltd. (NHC), British Columbia, Canada
}

\begin{abstract}
As the construction of infrastructure in and around a river channel modifies the flow and sediment transport characteristics, prediction of scour depths is an integral part of engineering design. Whilst there are a substantial number of predictive equations available to estimate the scour resulting from bridge piers, other types of structures have been less examined. This paper reports on flume experiments and numerical modelling to examine the role of submerged sills in the development of scour. Sills can be utilised in a channel to control bed stability, influence mixing dynamics or dictate water levels. Additionally, sills can occur due to infrastructure including riprap-covered pipeline crossings. The majority of previous work on sills has been undertaken on unsubmerged or partially submerged sills. The only experimental work on submerged sills is restricted to a range of conditions not applicable to pipeline crossings in large sandbed rivers. This paper presents experiments, using artificial light-weight sediment (crushed walnut shell), undertaken with a fixed flow depth but a range of velocities and sill heights, all of which are in the surface flow regime. Hydrodynamic numerical simulations were run for the same conditions to gain insight into the corresponding flow structure.
\end{abstract}

\section{Introduction}

Accurate estimates of scour are often required to prevent failure of structures that are constructed on alluvial rivers. Estimation of scour resulting from bridge piers has been extensively explored, resulting in a multitude of predictive equations (including [1-3]). However, other structures, such as sills which span over the width of a channel projecting from the bed into the flow, have been examined less extensively. Sills can be introduced as control structures, for example to influence bed stability, mixing dynamics or water levels. Alternatively, and as will be the focus of this research, sill-like structures may occur unintentionally as a by-product of engineering works. This paper forms part of an investigation to examine the effect of placing riprap aprons over pipeline crossings to prevent their exposure and potential damage. In some situations, for example due to general bed degradation, the riprap may protrude up into the flow, forming a sill and generating additional local scour.

The majority of previous work on sills has involved unsubmerged or partially submerged sills (e.g. [4-5]) which are not representative of riprap-covered pipeline crossings. However, recent research [6-7] has included an extensive dataset exploring the role of sill height $(Z)$, tailwater depth $(H)$, sediment size, and flow strength (indexed by velocity $(V) /$ critical velocity 
$\left.\left(V_{\mathrm{c}}\right)\right)$ upon scour depths downstream of submerged sills under both live-bed and clearwater conditions.

We are particularly interested in large sand-bedded channels (for example, the Fraser River in British Columbia, Canada), and when attempting to use the Guan et al. [6-7] dataset as a predictive tool, an issue arises. In the sand-bed section of the Fraser River, the channel has large flow depths, therefore low values of $Z / H$, and relatively high flow strengths, therefore high values of $V / V_{\mathrm{c}}$; the dataset [6-7] is capable of meeting both these requirements. However, the Guan et al. [6-7] experiments utilised sand $\left(D_{50}\right.$ of $0.26 \mathrm{~mm}$ and $0.85 \mathrm{~mm}\left(D_{\mathrm{x}}\right.$ denotes the grain size for which $\mathrm{x} \%$ is finer)), therefore at high $V / V_{\mathrm{c}}$ values the flow is in the impinging jet regime; conditions which are not representative of many low gradient, sand bed rivers such as the Fraser River, which is in the surface flow regime (for details of surface flow and impinging jet regimes, see [8]). This difference in the type of flow regime is significant, as Guan et al. [6] showed that the flow regime can have a substantial impact upon the scour depth, therefore eliminating the possibility of utilising the Guan et al.[6-7] dataset as a predictive tool.

To address this research gap, a series of experiments examining scour downstream of a submerged sill were undertaken using crushed walnut shell. By utilising crushed walnut shell, which is low density and therefore very mobile, it is possible to remain within the surface flow regime even for high $V / V_{\mathrm{c}}$ values; conditions representative of flow over riprap covered pipeline crossings in large sand-bed rivers, such as the Fraser River.

\section{Methods}

\subsection{Physical modelling}

\subsubsection{Experimental arrangement}

Experiments were undertaken in the laboratory at NHC, Vancouver, Canada. The experiments were exploratory, and therefore not scaled to a field case. The flume is $1.875 \mathrm{~m}$ wide, has a $10.85 \mathrm{~m}$ useable length and a $0 \%$ slope. To control the water level an adjustable tailgate is installed at the downstream boundary. Water is supplied, and the rate controlled, using a pump. The pump also recirculates sediment. The experiments utilised crushed walnut shell to form the sediment bed. The walnut shell has a specific gravity of 1.3 and $D_{50}$ of 0.2 $\mathrm{mm}$. The flume is equipped with an acoustic doppler velocimeter (ADV) and a laser-bed scanner. The laser-bed scanner measures the channel bathymetry, enabling the creation of digital elevation models. The scanner runs over a length of $6.9 \mathrm{~m}$, originating $3.4 \mathrm{~m}$ from the upstream boundary. The ADV is positioned at the channel centreline, $2 \mathrm{~m}$ from the upstream boundary, and was run with a sampling rate of $25 \mathrm{~Hz}$ and a sampling height of $7 \mathrm{~mm}$.

\subsubsection{Initiation conditions}

To evaluate the relative flow strength (velocity/critical velocity $\left.\left(V / V_{\mathrm{c}}\right)\right)$ in each experiment it was necessary to determine initiation conditions for the walnut shell $\left(V_{\mathrm{c}}\right)$. The following procedure was utilised to determine initiation conditions: (1) the bed surface was wetted and flattened using a scraper, (2) the flume was slowly filled to a flow depth of $30 \mathrm{~cm}$, and (3) the velocity in the channel was gradually raised by increasing the pump rate and lowering the tailgate (flow depth was consistently $30 \mathrm{~cm}$ ). At each velocity the walnut bed surface was monitored for several minutes for signs of entrainment. The bed was determined as being under 'initiation condition' once there were signs of entrainment upon the bed surface. The average velocity for initiation at $0.368 \mathrm{y}$ (y: flow depth) (distance from the bed) is taken to be 
$11.6 \mathrm{~cm} / \mathrm{s}$. The turbulent kinetic energy method outlined in Biron et al. [9] at $0.1 \mathrm{y}$ was utilised to estimate the dimensionless shear stress as 0.068 .

Assessing initiation is subjective and challenging. It must be acknowledged that the colour of the water in the flume experiments was dark brown due to the walnut shell. Whilst this was advantageous for generating high quality ADV measurements (with regards to signal-to-noise ratio), the dark water meant that entrainment conditions could only be assessed over a very limited distance close to the transparent sidewall. Consequently, the values determined represent our best estimate, but are not to be considered definite.

\subsubsection{Experimental procedure}

Ten experiments were undertaken with a range of velocities and two different sill heights $(Z)$ : $6 \mathrm{~cm}$ and $9.6 \mathrm{~cm}$ (see Table 1). Both sills were $2 \mathrm{~cm}$ wide, made of plexi-glass, and spanned the width of the flume orientated perpendicular to the flow. In all the experiments the flow depth $(H)$ was $30 \mathrm{~cm}$, therefore $Z / H$ ratios of 0.20 and 0.32 were tested.

The initial condition for the experiments was a flat bed. To prevent plunging flows over the sill at the start of the tests, the flume was slowly filled with water from both the upstream and downstream boundaries. Once the flow depth reached $30 \mathrm{~cm}$, the pump valve and the flume tailgate were varied until the velocity reached the desired value and the flow depth was at $30 \mathrm{~cm}$. The experiments were run until the bed reached equilibrium, which was determined by monitoring the bed profile through a plexi-glass sidewall.

Table 1. Summary of experimental conditions. In all experiments $H=30 \mathrm{~cm}$ and $V_{\mathrm{c}}=11.6 \mathrm{~cm} / \mathrm{s}$.

\begin{tabular}{|c|c|c|c|c|c|c|}
\hline No. & $\begin{array}{c}\text { Sill } \\
\text { height, } Z \\
(\mathrm{~cm})\end{array}$ & $\begin{array}{l}\text { Approach } \\
\text { velocity, } \\
V(\mathrm{~cm} / \mathrm{s}) \\
\end{array}$ & $V / V_{\mathrm{c}}$ & Froude & $\begin{array}{c}\text { Maximum } \\
\text { scour depth, } \\
D_{\mathrm{s}}(\mathrm{cm}) \\
\end{array}$ & $\begin{array}{c}\text { Distance of } \\
\text { maximum } \\
\text { scour, } L_{\mathrm{s}}(\mathrm{cm})\end{array}$ \\
\hline 1 & \multirow{7}{*}{6} & 8.94 & 0.77 & 0.05 & 0 & 0 \\
\hline 2 & & 16.26 & 1.40 & 0.09 & 0.63 & 32.5 \\
\hline 3 & & 27.75 & 2.39 & 0.16 & 4.13 & 42.5 \\
\hline 4 & & 34.88 & 3.01 & 0.20 & 14.5 & 92.5 \\
\hline 5 & & 41.69 & 3.59 & 0.24 & 15.38 & 117.5 \\
\hline 6 & & 42.75 & 3.69 & 0.25 & 16.75 & 114.38 \\
\hline 7 & & 46.60 & 4.02 & 0.27 & 25.13 & 133.13 \\
\hline 8 & \multirow{3}{*}{9.6} & 20.68 & 1.78 & 0.12 & 10.63 & 70.63 \\
\hline 9 & & 27.22 & 2.35 & 0.16 & 15.38 & 86.25 \\
\hline 10 & & 45.84 & 3.95 & 0.27 & 31.75 & 139.375 \\
\hline
\end{tabular}


Guan et al. [7] formulated Equation 1 to the Froude number at which the flow over a submerged sill transitions from the surface flow regime to the impinging flow regime; in this paper this will be termed the 'transitional Froude number', $F R_{\mathrm{t}}$. For $Z / H$ ratios of 0.2 and 0.32 , the corresponding transitional Froude numbers are 0.57 and 0.41 , respectively. When comparing the transitional Froude numbers with the values in Table 1, it is apparent that all the experiments presented herein are within the surface flow regime.

$$
F R_{\mathrm{t}}=-0.35 \ln (\mathrm{Z} / \mathrm{H})+0.01
$$

\subsection{Numerical modelling: CFD}

Computational fluid dynamics (CFD) modelling of the flume was undertaken using FLOW3D. The purpose of the CFD model was to gain insight into the flow structure within the flume, as direct measurement was not feasible. Two model runs were undertaken, both with a velocity of $47 \mathrm{~cm} / \mathrm{s}$ imposed at the upstream boundary and a flow depth of $30 \mathrm{~cm}$ at the downstream boundary. The first simulation incorporated a $6 \mathrm{~cm}$ high sill (corresponding to Experiment 7), and the second a $9.6 \mathrm{~cm}$ high sill (corresponding to Experiment 10). The mesh in the $\mathrm{x}, \mathrm{y}$ and $\mathrm{z}$ directions was $1 \mathrm{~cm}$, ensuring that the influence of $2 \mathrm{~cm}$ wide sill was captured. A roughness value $\left(k_{\mathrm{s}}\right)$ of $2 \times 10^{-6} \mathrm{~m}$ was utilised. This value was estimated by fitting a logarithmic profile to the vertical velocity profile measured in Experiment 7.

\section{Results}

Figure 1 presents the equilibrium scour profiles of Experiments 7 and 10; these experiments represent the highest flow velocities within the data set for each sill height. The maximum scour depth, $D_{\mathrm{s}}$, and the distance of the maximum scour, $L_{\mathrm{s}}$, are labelled for Experiment 7. Figure 1 illustrates that, for a given flow depth and this particular approach velocity, an increased projection of the sill into the flow results in a scour hole which is deeper and farther downstream. The positive correlation between sill projection and scour depth and distance demonstrated in Figure 1 was consistent for the range of velocities tested, as evidenced in Figure 2 and 3. 


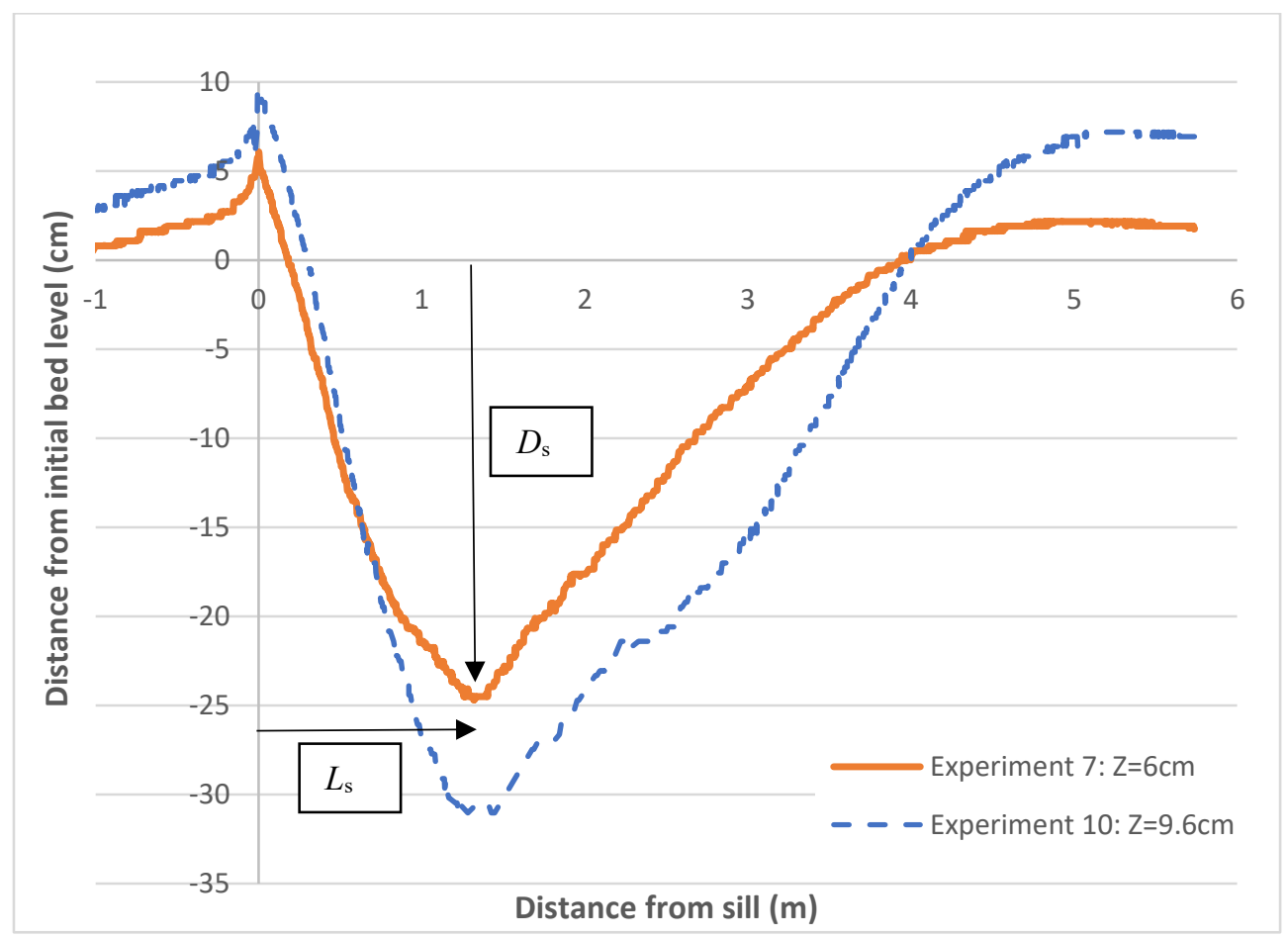

Fig. 1. Equilibrium bed scour profiles for Experiment 7 and 10. The maximum scour depth, $D_{\mathrm{s}}$, and the distance of the maximum scour, $L_{\mathrm{s}}$, are labelled for Experiment 7 .

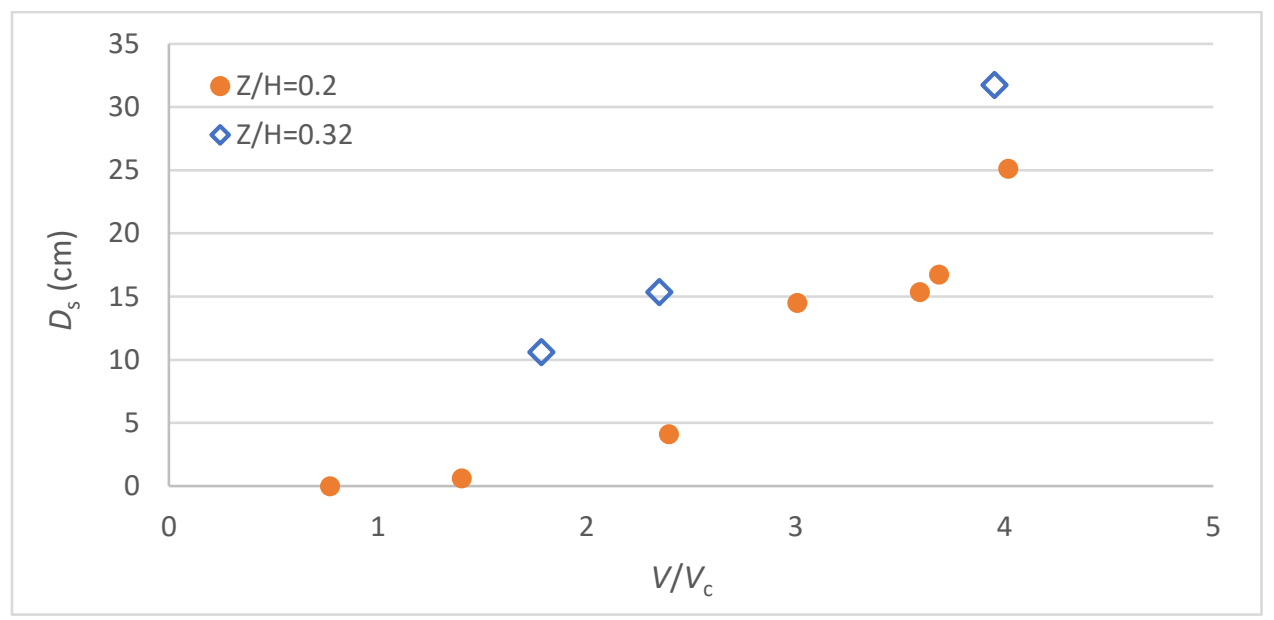

Fig. 2. Maximum scour depth, $D_{\mathrm{s}}$, as a function of flow strength, $V / V_{\mathrm{c}}$. 


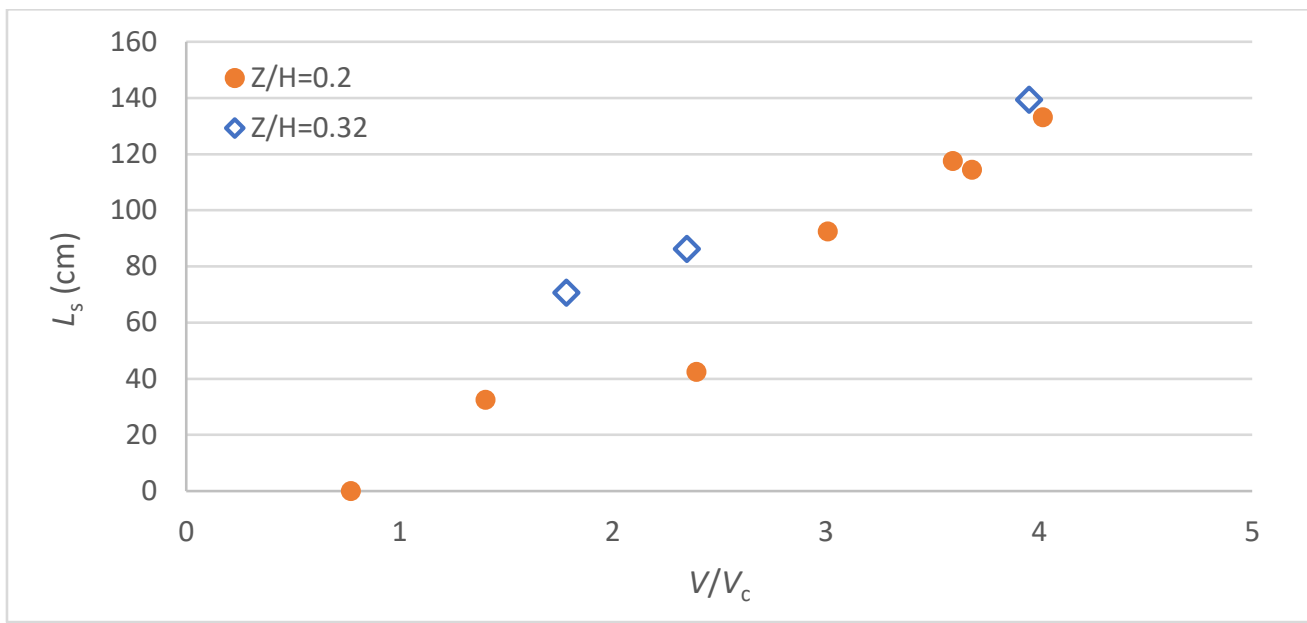

Fig. 3. Distance of maximum scour, $L_{\mathrm{s}}$, as a function of flow strength, $V / V_{\mathrm{c}}$.

Figure 4 and 5 present the streamwise velocity profiles, and corresponding flow vectors, for the FLOW-3D simulations undertaken with $6 \mathrm{~cm}$ and $9.6 \mathrm{~cm}$ high sills, respectively. The FLOW-3D simulations demonstrate how the size of the back eddy on the downstream side of the sill varies depending upon the sill height. Additionally, the flow structure illustrated in Figures 4 and 5 confirms that the experiments are within the surface flow regime (see [8]).

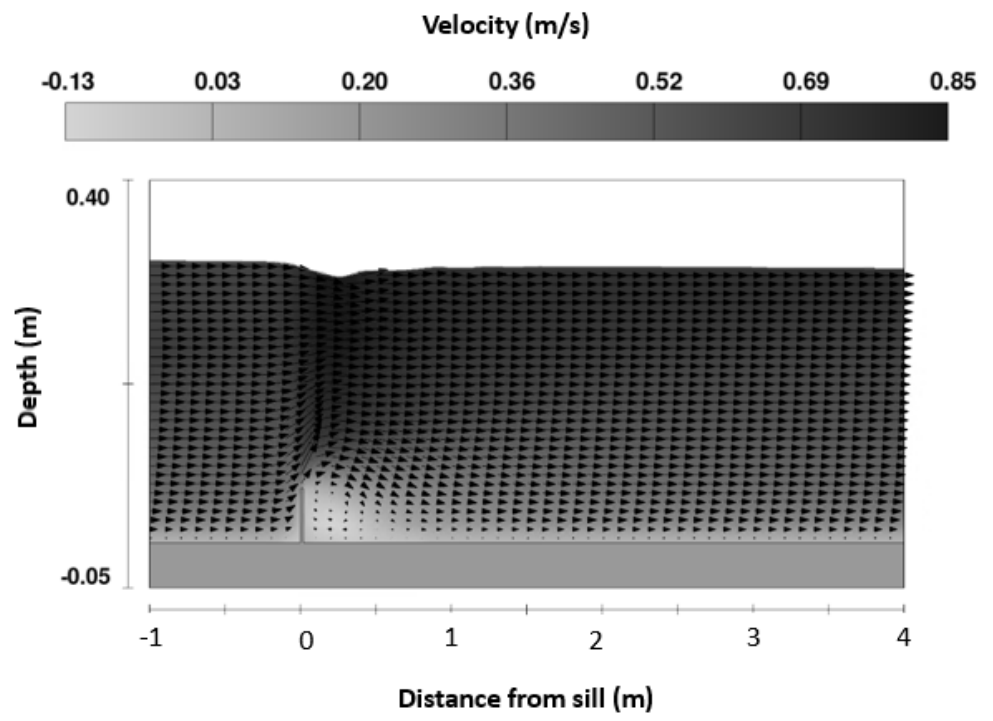

Fig. 4. Streamwise velocity profile simulated by FLOW-3D for a $6 \mathrm{~cm}$ high sill in a $30 \mathrm{~cm}$ deep flow. Velocity at the upstream boundary is $0.47 \mathrm{~m} / \mathrm{s}$. Corresponds to Experiment 7 . 


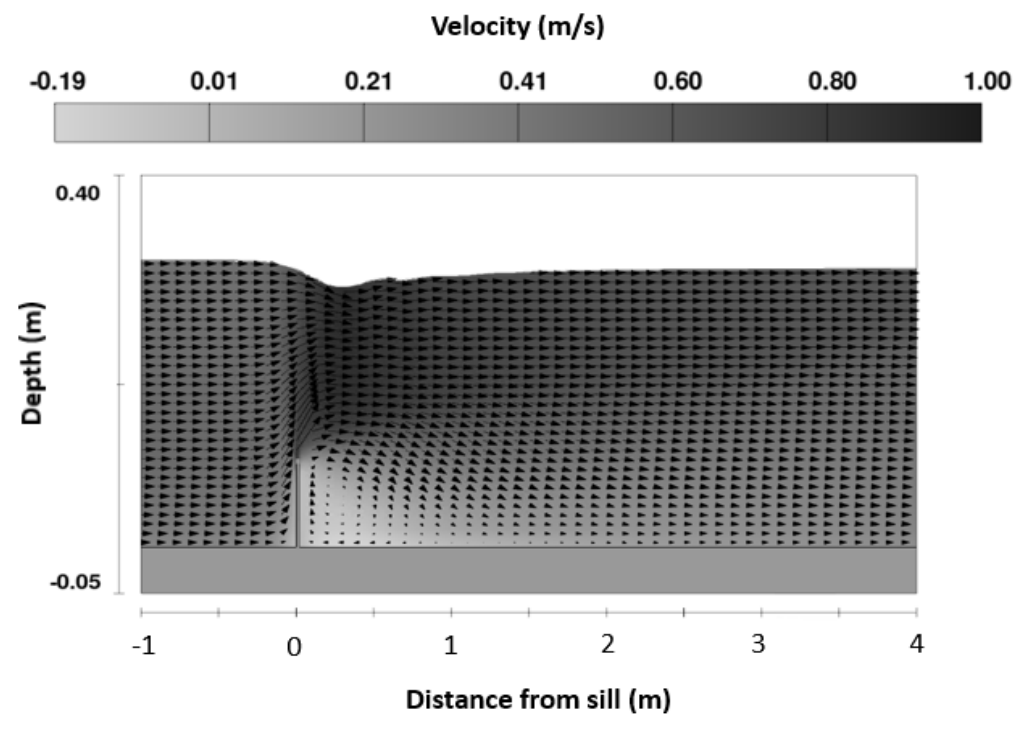

Fig. 5. Streamwise velocity profile simulated by FLOW-3D, assuming a $9.6 \mathrm{~cm}$ high sill in a $30 \mathrm{~cm}$ deep flow. Velocity at the upstream boundary is $0.47 \mathrm{~m} / \mathrm{s}$. Corresponds to Experiment 10 .

\section{Discussion and Conclusion}

The experiments demonstrate that increasing sill projection results in deeper scour, with the position of maximum scour occurring farther downstream (see Figures 1,2 and 3). The CFD simulations provide insight into this relation. In Figures 4 and 5 a back-eddy can be seen on the downstream side of the submerged sill. The occurrence of this back-eddy agrees with observations made during the flume experiments; within the scour hole walnut shell was observed to move upstream. Comparing Figure $5(Z / H=0.32)$ with Figure $4(Z / H=0.2)$ demonstrates that a higher sill (for a fixed flow depth) increases the magnitude and downstream length of the back-eddy, explaining the scour relation. This has important implications for engineering design. Bed degradation or dredging of river channels for navigation result in bed lowering and therefore the increasing projection of riprap covered pipelines into the flow.

For a given sill height, greater flow strengths (indexed by $V / V_{\mathrm{c}}$ ) increase the depth and distance of scour (see Figures 2 and 3). Distance of scour was not reported by Guan et al. [67] so it is not possible undertake a comparison. However, it is possible compare maximum scour depths. Figure 6 utilises the same axes as in Guan et al. [6-7] with $V / V_{\mathrm{c}}$ on the x-axis and $D_{\mathrm{s}} / H$ on the y-axis, and includes both our data and the data from [6-7] with similar $Z / H$ ratios including two different grain diameters (D). Figure 6 clearly illustrates that the data does not collapse, indicating that the dimensionless parameters utilised in the axes are not a good description of the physical processes determining scour downstream of sills. It is suggested that further work is needed to find a universal collapse of the data to enable its use as a predictive tool. It is proposed that this will require consideration of the flow regime and sediment properties. 


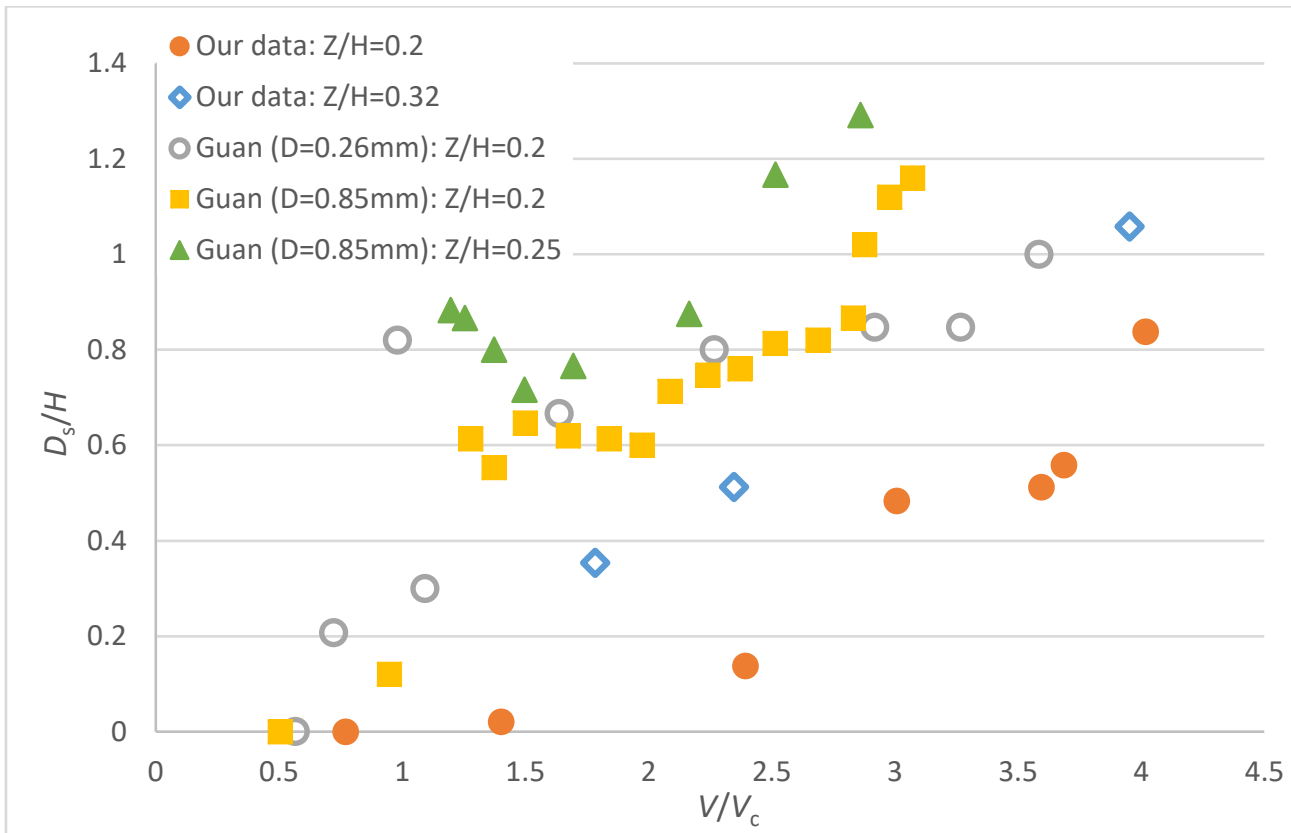

Fig 6. Maximum scour depth divided by tailwater depth as a function of flow strength $\left(V / V_{\mathrm{c}}\right)$ for our data and select Guan et al. [6-7] data.

This work was supported by Mitacs through the Mitacs Accelerate program and Northwest Hydraulic Consultants Ltd. The FLOW-3D simulations were undertaken using a research licence provided by Flow Science Inc. The flume experiments would not have been possible without the help of Paul Sampson, Ivan Diaz, Jomal Esguerra and Alex Moon.

\section{References}

1. E.M. Laursen, Scour at bridge crossings (Iowa Highway Research Board, Ames, 1958)

2. E.M. Laursen. J. Hydraul. Div. 89, 93-118 (1963)

3. D. Gao, G.L. Posada, C.F. Nordin, 1993. Pier scour equations used in the People's Republic of China FHWA-SA-93-076 (Federal Highway Administration, Washington, DC., 1993)

4. M.A. Lenzi, A. Marion, F. Comiti, ESPL 28, 99-110 (2003)

5. V. D’Agostino, V. Ferro, J. Hydraul. Eng. 130 (24), 24-37 (2004)

6. D. Guan, B.W. Melville, H. Friedrich, J. Hydraul. Eng. 141(2), 0401471 (2015)

7. D. Guan, B.W. Melville, H. Friedrich, J. Hydraul. Res. 54(2), 172-184 (2016)

8. S. Wu, N. Rajaratnam, J. Hydraul. Eng. 122(7), 412-414 (1996)

9. P.M. Biron, C. Robson, M.F. Lapointe, S.J. Gaskin. ESPL 29, 1403-1415 (2004) 